leading producers have partnered with auditors in independent certification bodies to field test the standards for salmon, bivalves and abalone, which will move into full use shortly.

Researchers, NGO staff and others should be aware that transparency and stakeholder participation is an integral part of the ASC process. There will be opportunities to influence environmental and social change in regions throughout the world by engaging in ASC assessments. The name and location of farms undertaking assessment will be posted on the ASC website (http://www.asc-aqua. org) 1 month prior to on-site audits, along with the names of proposed team members. Those interested in contributing to assessments for particular farms should contact the certification body responsible for a given assessment directly. Comments or concerns (including team composition) raised by members of both the public and private sectors will be incorporated into decisions made by assessment teams and audit reports will be publicly available via the ASC website.

SiÂN Morgan and SABINE DAUmE Scientific Certification Systems, 2000 Powell Street, Emeryville, California 95061, USA.

E-mailsmorgan@scscertified.com

Hank Cauley Paul G. Allen Family Foundation, Seattle, Washington, USA

CHRIS NINNES Aquaculture Stewardship Council, Utrecht, Netherlands

JoSE VILLALON Nutreco, Amersfoort, Netherlands

\section{American Association of Zoo Keepers: bowling for rhinos}

When black rhino Diceros biconrnis populations plummeted in the 1980s because of poaching, zoo keepers throughout North America took action to raise funds for conservation of the species: thus the Bowling For Rhinos fund-raiser began. At the same time as they spread the word about the plight of the black rhino, zoo keepers organized annual fund-raisers to secure money from the public to conserve rhinos in the wild. Since 1990 the American Association of Zoo keepers (AAZK) has sponsored Bowling For Rhinos, which has now raised over USD 4.3 million for conservation. Over 70 AAZK chapters participate throughout the USA and Canada, raising more than USD 300,000 annually. The funds are sent through Lewa USA, the International Rhino Foundation, and Action for Cheetahs in Kenya. The Association is currently developing a new campaign, in Australia. The funds raised by Bowling For Rhinos supports Lewa Wildlife Conservancy (formerly Ngare Sergoi rhino sanctuary) in Kenya, Ujung Kulon National Park in Java, Indonesia, Bukit Barisan Selatan National Park and Way Kambas in Sumatra, and Manas National Park in India. As well as contributing to saving all five rhino species, the funding helps secure organisms ranging in size from orchids to elephants. Conservation of rhino habitat is also helping to conserve the Endangered Grevy's zebra and the Critically Endangered hirola. The Bowling For Rhinos fund-raiser is now preparing for its 24th year. The programme is run entirely by volunteers, enabling $100 \%$ of all donations to go directly to conservation in the field. For more information please see http://aazkbfr.org

Patty Pearthree American Association of Zoo KeepersBowling For Rhinos, 318 Montibello Drive, Cary, NC 27513, USA.E-mail ppear3@pear3.org 